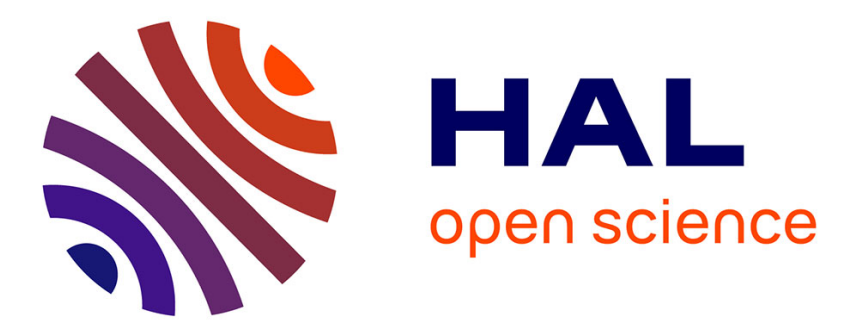

\title{
Pain and efficiency in neonatal blood sample screenings, New devices for reducing pain and improving blood sample quality
}

B. Wacogne, Ch. Pieralli, G. Cabodevila, N. Baron, S. Marioli, L. Pazart

\section{- To cite this version:}

B. Wacogne, Ch. Pieralli, G. Cabodevila, N. Baron, S. Marioli, et al.. Pain and efficiency in neonatal blood sample screenings, New devices for reducing pain and improving blood sample quality. Biodevices 2009, Jan 2009, Porto, Portugal. pp.290-295, 10.5220/0001776902900295 hal-00447674

\author{
HAL Id: hal-00447674 \\ https://hal.science/hal-00447674
}

Submitted on 6 May 2021

HAL is a multi-disciplinary open access archive for the deposit and dissemination of scientific research documents, whether they are published or not. The documents may come from teaching and research institutions in France or abroad, or from public or private research centers.
L'archive ouverte pluridisciplinaire HAL, est destinée au dépôt et à la diffusion de documents scientifiques de niveau recherche, publiés ou non, émanant des établissements d'enseignement et de recherche français ou étrangers, des laboratoires publics ou privés.

\section{(c)(1)}

Distributed under a Creative Commons Attribution| 4.0 International License 


\title{
PAIN AND EFFICIENCY IN NEONATAL BLOOD SAMPLE SCREENINGS New Devices for Reducing Pain and Improving Blood Sample Quality
}

\author{
Bruno Wacogne, Christian Pieralli \\ Institut FEMTO-ST, Département d'Optique P.M. Duffieux, UFR Sciences et Techniques \\ Route de Gray, 25030 Besançon cedex, France \\ Gonzalo Cabodevila, Nolwenn Baron \\ Institut FEMTO-ST, Département MN2S, Avenue de l'Observatoire, 25030 Besançon cedex, France \\ Sandrine Marioli \\ Service de Pédiatrie 1, CHU Saint Jacques, 2 place Saint Jacques, 25030 Besançon cedex, France \\ Lionel Pazart \\ Centre d'Investigation Clinique en Innovation Technologique, CHU Saint Jacques \\ 2 place Saint Jacques, 25030 Besançon cedex, France
}

\begin{abstract}
Keywords: Neonatal screening, pain evaluation, micro-needles arrays, image processing.
Abstract: Neonatal blood sample screening is recognised as a difficult gesture and painful to the newborns. The number of detected diseases is still relatively low and depends on the country where it is performed. There is a real need for new techniques that reduce pain, facilitate the blood sampling, increase the quantity of sampled blood and improve the collection of blood of the cardboard blotter actually used. In this paper, we present systems that are currently developed in Besançon (France) in collaboration between the FEMTO-ST Institute and the University Hospital. They mainly concern micro-needles arrays and pressure free blood sampling devices. The choice of these systems has been dictated by a study of the pain that newborns feel during the gesture. The ulterior motive of this work is to improve neonatal blood sample screenings and therefore, to increase the number of screened diseases and try to generalise this technique to places where it is not yet done.
\end{abstract}

\section{INTRODUCTION}

The blood sample screening of several congenital diseases (phenylketonuria, hypothyroidism, adrenal hyperplasia, ...) is performed routinely at birth in many countries. The number of detected diseases depends on the screening policy of the country and the technical limitations of the methods. For neonates, techniques are mainly limited by the difficulties of realisation of the sampling gesture, the small volume of punctionable blood and the pain caused by the gesture. Currently, the French Association for the Detection and Prevention of
Handicaps for Children (AFDPHE), responsible for organising the screening in France, favors (at the third day of life) a collection of capillary blood after a bite by a retractable lancet at the heel of the newborn. This gesture is followed by successive pressures on the heel in order to collect blood droplets on a cardboard blotter. This gesture is recognised as painful (Facchini, 2005), (Owens, 1984). It should be noted that in some places, screenings are performed with venous blood instead of capillary blood. In this case, the gesture is more technical and it presents risks for both the nurse and the newborn. In this paper, we restrict the discussion to the case of capillary blood. 
The orientation of the present works is intended to develop medical devices less painful and that offer a higher potential screening of a larger number of diseases in newborns, replacing technology currently used.

The context of the study, together with the evaluation of pain during the blood collection gesture is presented in section 2. Section 3 deals with the study of a painless micro-needles array meant to replace the classical lancet. In section 3, we present a device developed to obtain blood without successive pressures on the newborn's heel. Furthermore, this system can be used to efficiently deposit the collected blood on the cardboard blotter. Then, a conclusion and some perspectives will be proposed at the end of this manuscript.

\section{CONTEXT AND PAIN EVALUATION}

Screenings are achieved by nurses on the third day of life. They require the use of an automatic, sterile and disposable lancet that pierces the skin of the heel. The heel is then pressed to obtain droplets of blood that are collected on circles drawn on a cardboard blotter (as seen on figure 1). Since the blood flow is not sufficient, successive manual pressures to the heel are required. Circles on the card must be completely filled and the blood must cross the card (this is not the case for all the circles in figure 1). If the first attempt does not give enough blood, a second is made on the same heel or on the other one. In the same way, if the droplets do not cross the screening card it is necessary to add blood. This tracking is recognised as painful.

Newborns feel more or less pain during the blood sampling gesture. Pain can be estimated using various behavioural scales (Destuynder, 1991), (Uyan, 2008). Both D.A.N. (Douleur Aiguë du Nouveau-Né, Newborn Intense Pain ) and E.D.I.N. (Echelle de Douleur et d'Inconfort du Nouveau-Né, Newborn Pain and Discomfort Scale) scales are adapted to the evaluation of newborn's pain. We used the D.A.N. scale because it is more specific to intense pain. It allows quoting three criteria: the facial answer, the movements of the members and the vocal answer. Each criterion is quoted either between 0 and 3 or between 0 and 4 . We evaluated the pain at five different moments: before the gesture, when the nurse takes the baby's heel, during the lancet sting, when the nurse presses the heel and after the gesture.
For a first analysis, we observed 55 children for which 58 stings were needed. Indeed, no blood was obtained in 3 cases at the first attempt.

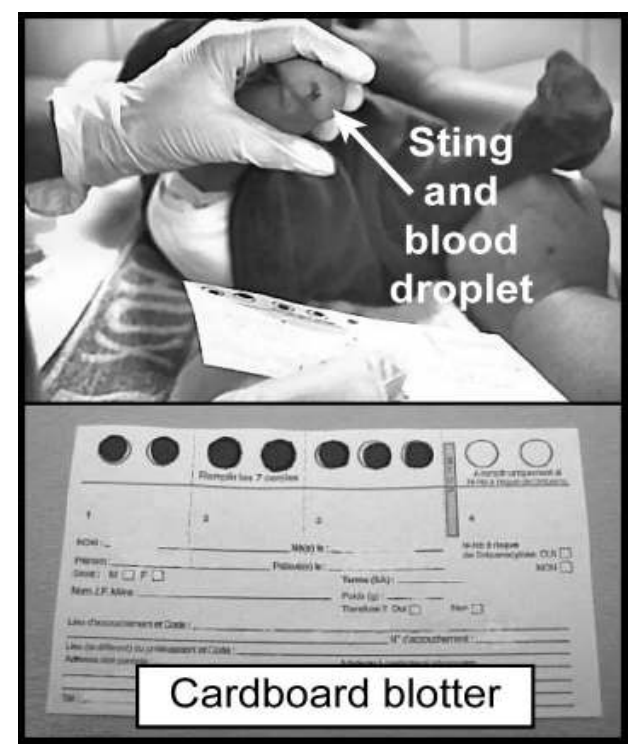

Figure 1: Actual blood sampling technique (top) and cardboard blotter used to collect blood.

The gesture proving to be painful for a majority of children, we refined our study at three moments: the taking of the heel, the sting, the pressing of the heel. The results obtained showed that the taking of the heel is not painful (only 1 case). The sting is painful in 10 cases, what nearly represents $25 \%$ of the cases. The pressing of the heel is the most painful moment (26 cases representing 68\%).

Therefore, we oriented our works toward two new systems of blood sampling. The first one is a micro-needles array meant to reduce the pain during the sting (in replacement of the lancet). The second one is used after the heel has been stung with the lancet. It is designed to collect enough blood without any pressure on the heel. Moreover, this system leads to a perfect impregnation of the cardboard blotter.

\section{MICRO-NEEDLES ARRAY}

The goal of this work is to estimate the geometry a micro-needles array used to collect blood at the newborn's heel. This array should replace the lancet. The goal is to penetrate the newborn's heel and to let blood flow in the holes of the micro-needles by capillarity. In a final version, a tank should be designed to store the sampled blood. Various studies concerning micro-needles have been published, but 
very little on blood collection. For example, we can mention the work presented by (Mukerjee, 2004). In this case, a liquid is obtained after a relatively long time but this liquid does not contain only blood. Other systems, inspired by mosquitos morphology, are presented but some complementary studies are still required (Oka, 2001), (Sharaf, 2003). Figure 2 shows an example of a micro-needles array fabricated in our laboratory. This particular architecture was designed for drug delivery and not for blood sampling.

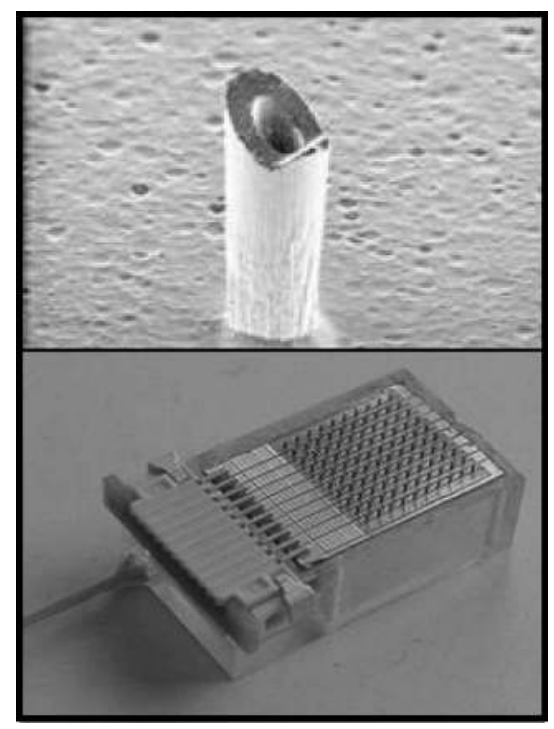

Figure 2: Example of micro-needles array fabricated in our laboratory.

For our specific application, the characteristics of the micro-needles have to be rethought according to the newborn's heel anatomy. The characteristics we studied are the shape, the dimensions and the number of micro-needles in a array. This work is based on a capillaroscopy study of the newborn's heels that helped to define the depth of the children's capillary network $(350 \mu \mathrm{m})$ and its density (70 capillaries by $\mathrm{mm}^{2}$ ). In what follows, we present the conclusion drawn from our studies. The details of numerical simulations can be obtained on demand.

Some parameters used in this study come from the work conducted for several years in our laboratory. Micro-needles are fabricated with silicon. The silicon surface is oxidized in order to make the device bio-compatible. The needles are cylindrical. In order to improve their strength the basis of the needles is conical. The tip of the needles is bevelled in order to facilitate the penetration of the stratum corneum. Finally, the needles exhibit a longitudinal slit. It is used to maximize the contact surface between the capillaries and the hole of the needle. Figure 3 shows a schematic diagram of one micro-needle.

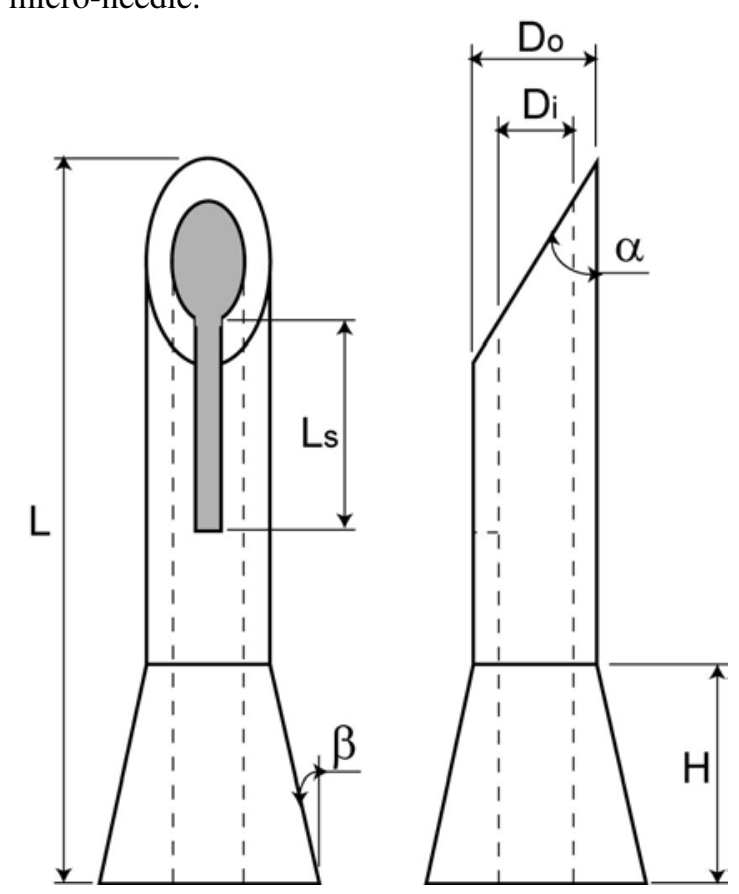

Figure 3: Schematic representation of a micro-needle dedicated for newborns blood sampling.

\subsection{Dimensions of the Needles}

The height $\mathrm{L}$ of the needles is fixed to $1200 \mu \mathrm{m}$ to ensure a penetration until the dermis of skin. The inner and outer diameters $\left(D_{i}\right.$ and $\left.D_{o}\right)$ are 60 and 150 $\mu \mathrm{m}$ respectively. These diameters increase the probability to meet a capillary.

The bevel exhibits an angle $\alpha=41^{\circ}$. This value is calculated considering that a third of the needle penetrates the skin $(400 \mu \mathrm{m})$ and that the hole of the needle must be at the level of the capillaries (350 $\mu \mathrm{m})$.

The slit must not extend outside the area where the capillaries are located. In this way, we reduce the risk to collect something else than blood. Its length is therefore limited to $L_{s}=200 \mu \mathrm{m}$. The width of the slit doesn't have an influence on the needle strength. Numerical simulations showed that the Von Mises constraints are almost not influenced by this parameter. For the moment, we consider a slit width of $60 \mu \mathrm{m}$.

The basis of the needle is conical. This cone is defined by its height $\mathrm{H}$ and its angular aperture $\beta$. Numerical simulations showed that the Von Mises constraints are minimized for a height $\mathrm{H}=600 \mu \mathrm{m}$ and an angular aperture $\beta<30^{\circ}$. 


\subsection{Probability to Collect Blood with the Needles}

To summarize, the micro-needles are cylindrical with a conical basis. They exhibit an opening used to collect blood. This opening consists of the hole of the needle and the longitudinal slit. When the microneedle has penetrated the skin, two surfaces can be defined: the total surface of the needle in skin and the surface of the opening that is susceptible to be in contact with the capillaries. The ratio between these two surfaces allows estimating the probability to collect blood.

Studies showed that an array of 8 needles gives a probability to collect blood equal to $67 \%$. It is necessary to increase the number of needles up to 24 to reach a probability of $96 \%$. We consider that the distance between two needles must be at least equal to $1 \mathrm{~mm}$. Below this size, the needles may not penetrate the skin (fakir effect). Therefore, a 24 needles array is about $4 * 6=24$ millimetre square, which is quite large. Another possibility is to use a 8 needles array ( 8 millimetre square) three times on three different parts of the heel.

\subsection{Perspectives}

To conclude this section, we have to mention that we are actually working on capillarity studies that should answer the question: how long will it take to collect enough blood ? It is indeed possible that a pumping system will be required in order to reduce the gesture duration.

Another aspect that must be addressed concerns the penetration of the needles into the skin. Techniques developed in the frame of other projects should be transposable to the specific anatomy of newborn's heel.

\section{PRESSURE FREE COLLECTION SYSTEM}

We recall that most of the children feel pain when their heel is pressed. The pressure on the heel is necessary to get the required quantity of blood in order to correctly fill the circles of the cardboard blotter. There are two main difficulties:

1. the quantity of the sampled blood with respect of the felt pain

2. the impregnation of the card circles; blood must cover the whole surface of the circles and the rear face of the card must be correctly impregnated.
To bring some solutions to these two constraints, a particular tip is studied (figure 4). This tip is fixed to the extremity of a reversed syringe that is not represented on the figure. The tip consists of a transparent bell onto which a micro-grid is stuck. A flexible interface is fixed on the micro-grid. The latter must be removable. It consists of thick disc with an aperture in its centre. We proceed as follows.

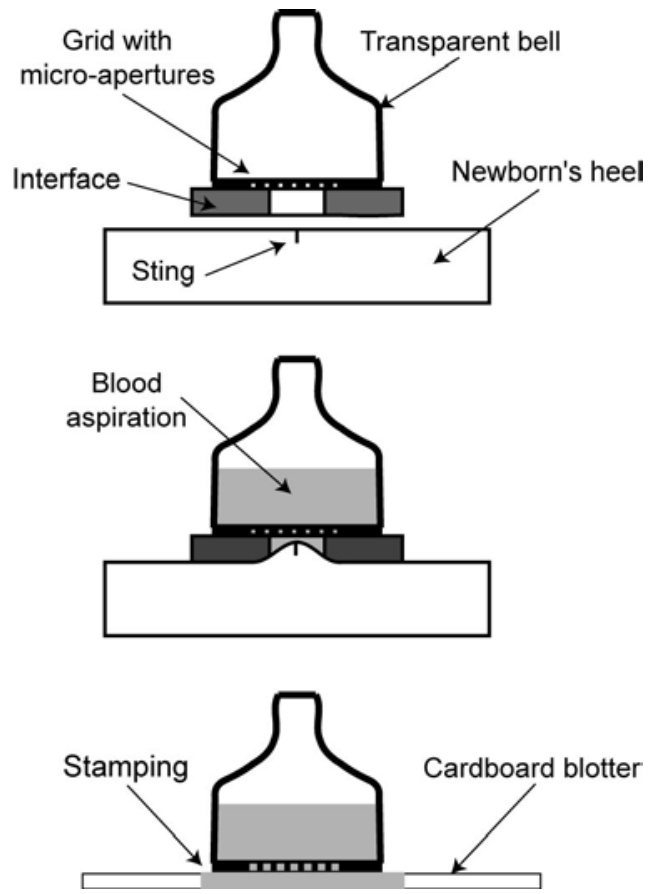

Figure 4: Principle of the pressure free system.

1. We pierce the newborn's heel with the conventional lancet.

2. We apply the device onto the cut. The flexible interface ensures the bloodproofness of the whole system and prevents the skin to be in contact with the micro-grid. Without this interface, the probability that the cut coincides with a few micro-apertures of the grid would be very weak and the quantity of sampled blood likely insufficient.

3. We start the aspiration by means of the reversed syringe. The pressure on the heel is no longer required.

4. Blood fills the transparent bell. The volume of the bell is fixed to $1 \mathrm{ml}$. We stop the aspiration when the bell is filled.

5. We withdraw the device from the heel.

6. We remove the interface. The dimension of the grid apertures is calculated so that blood remains in the bell during these operations. 
7. We apply the tip on the card. The apertures of the grid fill the whole surface of the circles printed on the card. By stamping, the circles are correctly filled. The capillarity forces are sufficient for blood to distribute efficiently.

Grids are micro-machined by Deep Reactive Ion Etching. Three characteristic dimensions of the apertures have been considered: $300 \mu \mathrm{m}, 200 \mu \mathrm{m}$ and $75 \mu \mathrm{m}$. Two grid thicknesses have been tested: $300 \mu \mathrm{m}$ and $525 \mu \mathrm{m}$.

The results presented here only concern the tests of homogeneity of the blood deposited on the cards. The blood aspiration through the grid will be tested subsequently. An example of grid attached to the transparent bell is shown in figure 5 .

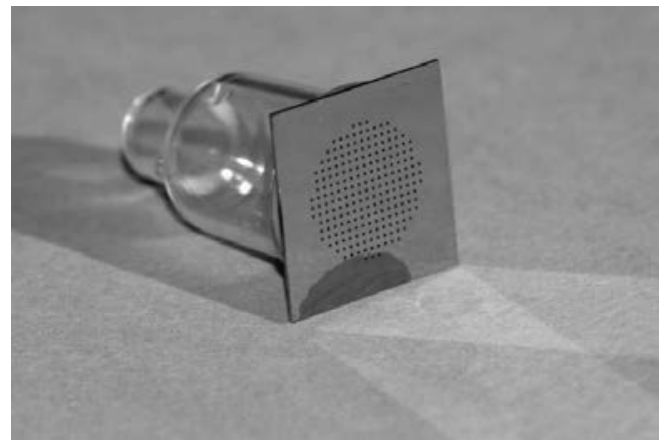

Figure 5: View of a micro-machined grid fixed on a transparent bell.

We analyzed the uniformity of the blood collection with the help of a light source equipped with a diffuser that permits to illuminate the cardboard blotter in a homogeneous manner. A CCD camera is used to acquire pictures of the different blood impregnated circles. Finally, a suitable image processing is used to measure the uniformity of blood. An example of impregnated card is presented on figure 6 (top). In this case, only $800 \mu \mathrm{l}$ was necessary to completely fill the circles. Besides, no pressure on the syringe was required, the capillarity forces being sufficient. The homogeneity of the blood is clearly observed. Also, we can note that blood completely crosses the card as it can be seen in figure 6 (bottom). In all, six cards have been impregnated with grids of different thicknesses and apertures of various dimensions.

Two steps are required to evaluate the homogeneity by image processing. The first one consists in semi-automatically detecting the circle that contains blood. The second one consists in evaluating the homogeneity of the blood. To do this, the pictures are convolved with a test window of $5 \times 5$ then of $25 \times 25$ pixels. We calculate the standard deviation on the considered window; the lower the standard deviation, the better the homogeneity. A typical result is given in figure 7 where the homogeneities obtained with apertures of 300 and 75 $\mu \mathrm{m}$ are shown. In abscissa we have the number of the card and in ordinates the value of the homogeneity indicator.

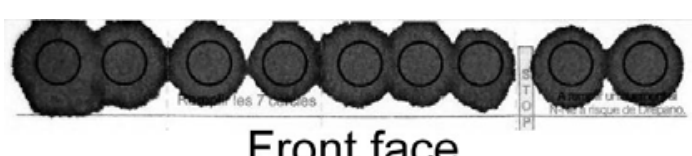

Front face

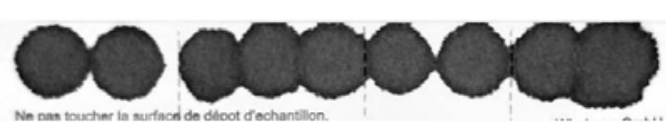

Rear face

Figure 6: Picture of both front and rear side of a cardboard blotter impregnating with the pressure free device.

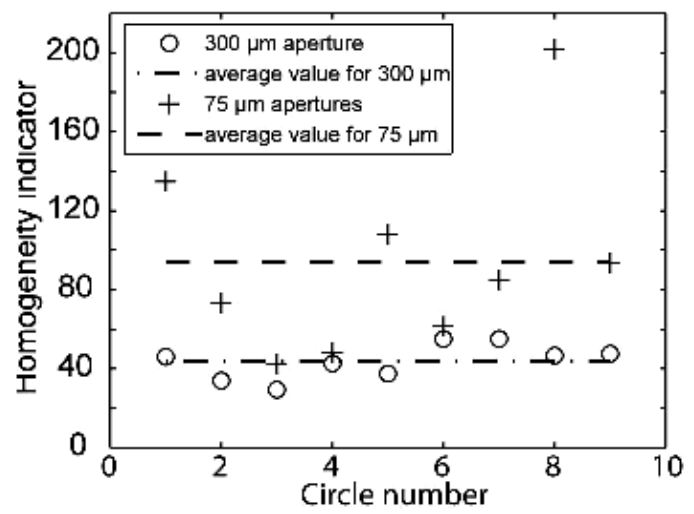

Figure 7: Experimental estimation of the homogeneity of the cardboard blotter impregnation for two aperture sizes.

The conclusion seems obvious. For equal microgrid thicknesses, homogeneity is better for large apertures than for small ones. The grid thickness has no influence. $300 \mu \mathrm{m}$ apertures seem interesting for two reasons. First, the apertures are small enough so that the blood doesn't escape from the grid before the latter is in contact with the cardboard blotter. Secondly, such a dimension is compatible with the industrial machining. The manufacture of such tips will therefore be cost-effective.

\section{CONCLUSIONS}

In this paper, we have presented new medical devices that reduce pain and should allow screening a larger number of diseases in newborns. They are meant to replace the technology currently used in 
neonatal blood sample screening. The origin of this work is a study of the pain felt by the newborns. This has highlighted that both, the sting and the pressure required for the blood collection where painful. We therefore studied a micro-needles array as well as a system that suppresses pressures on the children's heel. The ulterior motive of this work is to improve neonatal blood sample screenings and therefore to increase the number of screened diseases and try to generalise this technique to a places where it is not yet done.

\section{ACKNOWLEDGEMENTS}

This work is supported by the French Health Ministry through a Hospital Protocol for Clinical Research.

\section{REFERENCES}

Destruynder, R., Lassauge, F., Menget, et al., 1991, Pain in the newborn in an intensive care unit, Pediatrie, Vol. 46, pp. 535-539.

Facchini, A., Bellieni, CV., 2005, Relating pain intensity of newborns to onset of nonlinear phenomena in cry recordings, Physics Letters A, Vol. 338, pp. 332-337.

Mukerjee, E., Collins, S., Isserof, et al., 2004, Microneedles array for transdermal biological fluid extraction and in situ analysis, Sensors and Actuators A, Vol. 114, pp. 267-275.

Oka, K., Aoyagi, S., Isono, et al., 2001, Fabrication of a micro-needle for a trace blood test, Transducer'01 Digest of Technical Papers, pp. 412-415.

Owens, ME., Todt, EH., Pain in infancy : neonatal reaction to a heel lance, 1984, Pain, Vol. 20, pp. 7786.

Sharaf, R., Aggarwal, P., Kaler, K., et al., 2003, On the design of an electronic mosquito : design and analysis of the micro-needle, Proceedings of the International Conference on MEMS, NANO and Smart Systems, pp. 32-35.

Uyan, ZS., Bilgen, H., Topuzoglu, et al., Comparison of three neonatal pain scales during minor painful procedures, 2008, Journal of Maternal-Fetal and Neonatal Medicine, Vol. 21, pp. 305-308. 